\title{
EL PRINCIPIO DISPOSITIVO DE LA CASACIÓN
}

Samir Alberto Bonett Ortiz*

\section{ReSUMEN:}

Es de la naturaleza de la casación el principio dispositivo, que significa que la Corte o Tribunal de Casación no puede actuar de oficio, sino que está limitada por la demanda de casación. Esto lo dijo Piero Calamandrei, fundado en que el derecho de impugnación de casación de la sentencia hace parte del derecho de acción y este, siguiendo a Guiseppe Chiovenda, es un derecho potestativo. Luego, el derecho de impugnación de casación también es un derecho potestativo y no puede la Corte o Tribunal de Casación actuar de oficio. Esta idea de Calamandrei ha sido aceptada ciegamente por la normativa, jurisprudencia y doctrina, pero tiene un error en su fundamentación que la hace inaceptable, no solo hoy, sino que ha debido ser rechazada desde que se criticó la tesis de Chiovenda, pero no ha sido cuestionada, y ese es el fin de este estudio. La conclusión, de probarse el error teórico (dogmático) e histórico, sería que la Corte o Tribunal de Casación puede actuar de oficio aplicando el principio iura novit curia.

Palabras clave: Derecho de acción, derecho potestativo, Guiseppe Chiovenda, Piero Calamandrei y principio dispositivo de la casación.

\section{Abstract:}

This is the nature of the cassation the principle device, which means that the Court of Cassation cannot act on its own, but is limited by the demand of cassation. This Piero Calamandrei founded said that the right to challenge on cassation of the judgment is part of the right of action and this, following

* Abogado, Universidad Libre de Colombia, 2004. Especialista en Derecho Laboral. Universidad Libre de Colombia, 2005. Secretario del Instituto Colombiano de Derecho Procesal, Capítulo Norte de Santander. Docente Investigador de la Universidad Libre Seccional Cúcuta. Director del Semillero de Derecho Procesal de la Universidad Libre Seccional Cúcuta.

Este artículo no ha sido publicado. 


\begin{abstract}
Guiseppe Chiovenda is a discretionary right. Then, the right to challenge on cassation is also discretionary and cannot right the Court of Cassation act automatically. Calamandrei this idea has been accepted uncritically by the regulations, case law and doctrine, but has an error in its reasoning that makes it unacceptable, not just today, but had to be rejected since Chiovenda criticized the thesis, but not been questioned, and that is the end of this study. The conclusion, to prove the theoretical error (dogmatic) and historic, would be for the Court of Cassation may act on its own using the iura novit curia.
\end{abstract}

Keywords: right action, right optional, Guiseppe Chiovenda, Piero Calamandrei and principle of the matching device.

\title{
INTRODUCCIÓN
}

En ocasiones la autoridad de un gran procesalista hace que sus ideas no sean sometidas a crítica y esto ha pasado con Piero Calamandrei y su obra La Casación Civil, especialmente con su idea del principio dispositivo de la casación. Todos, la normativa, jurisprudencia y doctrina, han repetido su idea, sin detenerse a estudiar su fundamentación, y han cometido un gran error teórico (dogmático) e histórico que ha tenido graves consecuencias en la tutela judicial efectiva por la pasividad de las Cortes o Tribunales de Casación del mundo. No se trata sólo de un aspecto teórico, sino principalmente de la impartición de justicia, como el mismo Calamandrei dijo, de una justicia sustancial ${ }^{1}$.

Y es que es un dogma en el derecho procesal que es de la naturaleza de la casación el principio dispositivo. Pensar lo contrario sería ir en contra de una tradición procesal y de la obra de Calamandrei, "el teórico más importante de la casación”2, quien fundamentó esta idea. Sin embargo, en esta idea hay un gran error teórico (dogmático) e histórico que no se ha cuestionado.

El estudio se hará en dos partes: primera, la importancia de la obra de Piero Calamandrei; y segunda, el principio dispositivo de la casación, haciendo las críticas y probando el gran error teórico (dogmático) e histórico, para terminar con una propuesta y conclusiones.

\section{La importancia de la obra de Piero Calamandrei}

La Casación Civil de Piero Calamandrei fue publicada en 1920 cuando apenas contaba treinta y un años; Calamandrei (1889-1956), profesor italiano de la Universidad de Florencia, es considerado uno de los grandes procesalistas de la

1 CAlamandreI, P. Instituciones de Derecho Procesal Civil. Volumen III. Traducción de Santiago Sentís Melendo, Buenos Aires: Librería El Foro SA, 1996. p. 249-250.

2 BONETT ORTIZ, Samir Alberto. "La Casación Laboral Justa". En: XXXIII Congreso Colombiano de Derecho Procesal. Cartagena de Indias, 2012. Memorias. p. 813. 
historia, discípulo de Carlos Lessona y Guiseppe Chiovenda, contemporáneo de Francesco Carnelutti y Enrico Redenti, y maestro de muchos, entre ellos, Santiago Sentís Melendo, principal traductor de su obra del italiano al español.

"Según Santiago Sentís Melendo3, el aporte de La Casación Civil de Piero Calamandrei, «... como obra de juventud ${ }^{4}$ parece un milagro. Nada se había escrito hasta entonces, ni se ha producido después, que se le pueda comparar en extensión y, sobre todo, en profundidad. Su influencia no se manifestó tan sólo en la doctrina, sino también en la legislación; la obra de Calamandrei fue, sin duda alguna, la que más influencia tuvo para que en Italia terminase "la absurda rareza de la unidad pluralizada, el fenómeno jurídico de la coexistencia en un Estado de cinco organismos

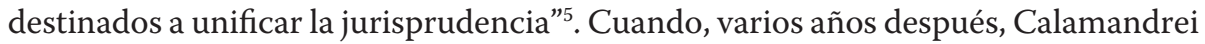
escribió, para el Nuovo Digesto, la voz Cassazione civile, el absurdo había desaparecido y la unidad del órgano de interpretación se había logrado; su esfuerzo no había sido inútil" (cursiva del texto), (subrayado fuera de texto). Aunque, como dice Jordi Nieva Fenoll ${ }^{6}$, “...algunas de sus ideas, teniendo en cuenta quién las decía, han influido muchísimo en la doctrina, que, como suele ocurrir, las ha exacerbado y han resultado en parte devastadoras para la utilidad del recurso» ${ }^{7 ”}$.

\subsection{La influencia de la obra de Piero Calamandrei en Colombia}

En Colombia, la influencia de la obra de Piero Calamandrei sobre el principio dispositivo es total: se aceptó, casi en silencio, sin ninguna duda, especialmente por las dos principales obras de doctrina sobre casación: Hernando Morales Molina ${ }^{8}$ no dice nada al respecto, y Humberto Murcia Ballén ${ }^{9}$ se limita a citar a la Corte Suprema de Justicia, quien a su vez cita al profesor italiano: "La apuntada limitación

3 CALAMANDREI, P. "El Hombre y la Obra". Prólogo a Instituciones de Derecho Procesal Civil. Volumen I. Traducción de Santiago Sentís Melendo, Buenos Aires: Librería El Foro SA, 1996. p. 43.

4 El pie editorial es de 1920, o sea cuando Calamandrei tenía treinta años; pero todavía ha de añadirse que esa obra, publicada después de la guerra, hubo de escribirse, si no en su totalidad, al menos en su mayor parte, antes de que Calamandrei, en 1915, se incorporase al ejército, según él mismo refiere en el Prefacio al primero de los tomos. Esta nota es de la cita.

5 Calamandrei relata en ese prólogo su conversación con un magistrado de la Corte de Casación de Viena, en la que comparaban instituciones procesales de ambos países; y el asombro del magistrado austríaco ante "la unidad pluralizada". Esta nota es de la cita.

6 NIEVA FENOLL, Jordi. "La Relevancia Social de la Casación: la Importancia del Ius Litigatoris". Ponencia presentada en el XXVII Congreso Colombiano de Derecho Procesal, Cartagena de Indias, 2006. Memorias. pp. 587-614. Las notas 3 a 6 son de la cita.

7 BONETT ORTIZ, Samir Alberto. Op. cit., pp. 816-817.

8 MORAleS MOlinA, Hernando. Técnica de Casación Civil. $2^{\text {a }}$ ed., (edición privada).

9 MURCIA BALLÉN, Humberto. Recurso de Casación Civil. 2a ed., Bogotá: Editorial Temis Librería, 1978. pp. 20-21. 
[de actuar de oficio] la sintetiza y explica así la Corte: "No puede [la Corte] examinar de oficio defectos de la sentencia que no hayan sido denunciados formalmente por el recurrente, y decidir la invalidación del fallo por errores no invocados en la demanda de casación. (...) Dice el procesalista PIERO CALAMANDREI...", lo que viene a continuación es la transcripción de la obra de Calamandrei.

Entonces, en Colombia, como en el mundo, el fundamento del principio dispositivo de la casación es lo dicho por Calamandrei; no se estudió la fundamentación teórica de dicho principio para saber si era correcta o no. Algo así como "lo dijo Calamandrei y punto".

\section{El PRINCIPIO DISPOSITIVO DE LA CASACIÓN}

\subsection{El principio dispositivo en el derecho procesal}

Según Lino Enrique Palacio" "Llámase principio dispositivo a aquel en cuya virtud se confía a la actividad de las partes tanto el estímulo de la función judicial como la aportación de los materiales sobre los cuales ha de versar la decisión del juez. La vigencia de este principio se manifiesta en los siguientes aspectos: iniciativa, disponibilidad del derecho material, impulso procesal, delimitación del thema decidendum, aportación de los hechos y aportación de la prueba" (cursiva del texto).

Llevado el principio dispositivo a la casación, significa que la Corte o Tribunal de Casación no puede actuar de oficio, sino que está limitada por la demanda de casación.

\subsection{Idea}

¿Cuál es el fundamento del principio dispositivo de la casación?, ¿por qué dijo Piero Calamandrei que en la casación se debe aplicar el principio dispositivo? Es necesario transcribir la explicación del profesor italiano para mayor claridad.

«Según Piero Calamandrei ${ }^{11}$, la casación se rige por el principio dispositivo: “... la Corte de casación no puede poner de relieve de oficio defectos de la sentencia denunciada no deducidos en el recurso ${ }^{12}$. Si el recurso del particular fuese solamente el medio para poner en movimiento la Corte de casación en interés público, para excitarla a indagar objetivamente, en utilidad del Estado, si el ordenamiento jurídico ha sido violado por la sentencia denunciada, se podría pensar que la Corte de casación, una vez puesta en movimiento, fuese libre de anular la sentencia

10 Manual de Derecho Procesal Civil. 19ª ed., reimpresión, Buenos Aires: Abeledo Perrot S.A, 2009. p. 63.

11 CALAMANDREI, Piero. Op. cit., pp. 172-174.

12 CHIOVENDA, Principii, p. 1054. Esta nota es de la cita. 
también por errores de derecho in iudicando diversos de los puestos de relieve por el recurrente, desde el momento en que la regla Iura novit curia pondría a la Corte de Casación en situación de hacer una crítica directa sobre toda la motivación in iure de la sentencia denunciada, y de darse inmediatamente cuenta de todas las violaciones de ley contenidas en ella, aunque hubieran escapado a la crítica del recurrente.

A esta conclusión es, en cambio, imposible llegar si se tiene presente que el objeto de la sentencia de la Corte de Casación es la existencia de una concreta voluntad de ley que garantice el interés del recurrente en obtener la anulación, y que el recurrente hace valer ante la Corte de casación un derecho suyo de impugnación basado sobre aquel vicio singular que él denuncia en el recurso. El derecho de casación que la ley atribuye al particular es un derecho potestativo, esto es, un poder jurídico del recurrente de producir la anulación de la sentencia denunciada mediante sentencia de juez ${ }^{13}$ : este derecho potestativo no difiere de aquellos derechos de impugnación que el derecho privado concede en algunos casos contra un negocio jurídico viciado por determinados defectos ${ }^{14}$, sino en cuanto, mientras los mismos tratan de producir una variación en una situación nacida del derecho privado, éste trata de producir una variación en una situación jurídica que se ha formado como consecuencia de una providencia procesal (sentencia) ${ }^{15}$; pero el diverso origen de las situaciones jurídicas que el derecho de impugnación trata de remover, no supone que el derecho a obtener la anulación de una sentencia, por un defecto que la vicia, deba ser tratado procesalmente de un modo diverso que el derecho a obtener la anulación de un negocio de derecho privado, defectuoso y, por esto, anulable. Ahora bien, de la misma manera que el derecho de impugnación de un negocio de derecho privado se concreta por la existencia de un hecho jurídicamente relevante, esto es, por la existencia de un vicio que la ley considera como motivo de anulabilidad, así el derecho de casación de una sentencia se apoya sobre la existencia de una determinada violación de ley, la cual, cuando este derecho es hecho valer ante el juez, constituye la causa petendi de la acción de impugnación, esto es, uno de los elementos en los cuales la acción misma se individualiza y se hace recognoscible frente a cualquiera otra acción. Cada error de interpretación existente en la sentencia es el hecho constitutivo de un separado derecho de impugnación; y como el recurrente, al denunciar un determinado vicio de la sentencia, pretende con ello hacer valer el derecho de impugnación nacido de este vicio singular, no podría la Corte de Casación anular la sentencia por un

13 CHIOVENDA, Principii, p. 180; Azione, n. 13. Más adelante, n. 84. Esta nota es de la cita.

14 CHIOVENDA, Azione, pág. 109, enumera sin distinción entre los derechos potestativos "los derechos de impugnar actos jurídicos diversos, contratos, testamentos, matrimonios... sentencias, actos ejecutivos" (cursiva del texto). Esta nota es de la cita.

15 HELLWIG, System, $\mathbb{\$} 17$, II, 3 c. Esta nota es de la cita. 
vicio diverso del denunciado, sin juzgar sobre una acción absolutamente diversa de la hecha valer y sin incurrir, por tanto, en extra petita. La particularidad del caso, que podría dar lugar a alguna confusión de ideas, es ésta: que mientras para las impugnaciones de negocios de derecho privado el hecho constitutivo del derecho de impugnación es un hecho que el juez no puede tener en cuenta sino en cuanto esté probado por la partes (por ejemplo, la captación), para la impugnación de la sentencia que el recurrente hace valer en la Casación el hecho constitutivo del derecho de impugnación es la existencia de un error de derecho, el cual, en un juicio de mérito, podría ser puesto de relieve directamente por el juez, sin necesidad de pruebas, en virtud del principio Iura novit curia. Pero la especial función que este error de derecho ejercita en casación -esto es, la de ser el elemento constitutivo de un derecho de impugnación- obliga al juez, en esta sede, a considerarlo como un hecho, esto es, a ver en él cuando sea denunciado por el recurrente, la causa petendi de la acción deducida en juicio, mientras otros errores de derecho que el juez de casación estaría en situación de poner de relieve de oficio en la sentencia impugnada no pueden ser considerados aquí como motivos de anulación, porque constituyen tantas causae petendi de otras tantas acciones de impugnación que el recurrente habría podido ejercitar, pero que no ha ejercitado ${ }^{16 "}$ (cursiva del texto), (subrayado fuera de texto).

Advierto que para Piero Calamandrei, el principio dispositivo sólo se fundamenta en ser la acción de impugnación de casación un derecho potestativo, y no deriva de la naturaleza extraordinaria de la casación o de que no es una tercera instancia (cursiva y subrayado del texto) ${ }^{17} »$.

\subsection{Aplicación}

El principio dispositivo de la casación ha llevado a que las Cortes o Tribunales de Casación del mundo, incluida Colombia, estén limitadas por la demanda de casación, e incluso, en caso de evidente violación del ordenamiento jurídico (que es el aspecto negativo del fin público de la casación [casar o destruir la sentencia del tribunal que viola el ordenamiento jurídico - de ahí lo de aspecto negativo-]), pero no impugnada por el recurrente o ante la deficiente demanda. Basta citar un ejemplo dramático en la casación laboral colombiana:

"El caso de Florentino Enrique Méndez Espinoza, por sentencia del 18 de octubre de 2000, exp. 13.396, M.P. Luis Gonzalo Toro Correa, la Corte Suprema de Justicia, Sala de Casación Laboral, consideró: "No obstante que por razones de técnica la acusación no tuvo éxito, la Corte hace la corrección doctrinaria al Tribunal, en la medida en que debió considerar que, pese a que el actor llevaba más de 15 años

16 CHIOVENDA, Principii, p. 285; GATTI, Autorità del giudicato civile, n. 19. Esta nota es de la cita. Las notas 11 a 16 son de la cita.

17 BONETT ORTIZ, Samir Alberto. Op. cit., pp. 821-823. 
de servicio a la fecha de expedición de la Ley 33 de 1985, también lo era que tenía laborados más de 20 años al estado, en condición de empleado oficial, de donde resultaba beneficiario de la pensión de jubilación en los términos previstos por el inciso primero de la mencionada norma" (subrayado fuera de texto) ${ }^{18}$ ".

Igualmente la Sala de Casación Civil y Agraria de la Corte Suprema de Justicia ${ }^{19}$ y la Corte Constitucional ${ }^{20}$ sostienen el principio dispositivo y su alcance, aunque la última considera: "La naturaleza irrenunciable de tales derechos (fundamentales) prima sobre el carácter dispositivo que en términos generales tiene la casación".

\subsection{Crítica}

La crítica al principio dispositivo de la casación se puede hacer desde dos puntos de vista: 1) desde el punto de vista de la concepción del Estado social de derecho y sus manifestaciones y 2) desde el punto de vista teórico o dogmático.

\subsubsection{Crítica desde el punto de vista de la concepción del Estado Social de Derecho y sus manifestaciones}

El Estado Social de Derecho, la Constitución Política y los derechos fundamentales serían razones suficientes para rechazar el principio dispositivo de la casación por la injusticia de la mayoría de casos.

Esta concepción del Estado social de derecho ha llevado a atenuar el principio dispositivo. "En Colombia, en un avance, el art. 184, inc. 3 del Código de Procedimiento Penal ordena a la Corte Suprema de Justicia decidir el recurso de casación de oficio, así: «En principio, la Corte no podrá tener en cuenta causales diferentes de las alegadas por el demandante. Sin embargo, atendiendo a los fines de la casación, fundamentación de los mismos, posición del impugnante dentro del proceso e índole de la controversia planteada, deberá superar los defectos de la demanda para decidir de fondo" (subrayado fuera de texto). Siguiendo la misma tendencia, el art. 336, inciso final del Código General del Proceso establece: «La Corte no podrá tener en cuenta causales de casación distintas de las que han sido expresamente alegadas por el demandante. Sin embargo, podrá casar la sentencia, aun de oficio, cuando sea ostensible que la misma compromete gravemente el orden o el patrimonio público, o atenta contra los derechos y garantías constitucionales» (subrayado fuera de texto)" ${ }^{\prime 21}$ ¿ ¿Y la casación laboral cuándo avanzará?

\footnotetext{
18 BONETT ORTIZ, Samir Alberto. Op. cit., p. 838.

19 Colombia. Sentencia del 23 de marzo de 2000, exp. 5259, M.P. Carlos Ignacio Jaramillo Jaramillo.

20 Colombia. Sentencia T-1306 del 6 de diciembre de 2001, M.P. Marco Gerardo Monroy Cabra. 
"Asimismo, el Derecho Comparado ${ }^{22}$ prueba que el principio dispositivo del recurso de casación laboral -criterio aplicable a los recursos civil y penal- no es de la esencia del mismo, más aún es incompatible, y por el contrario, el principio iura novit curia permite cumplir los fines, es decir, que la Corte puede ir más allá de lo pedido. En Venezuela, el art. 175, inc. 4 de la Ley Orgánica Procesal del Trabajo del 13 de agosto de 2002, consagra: «Podrá también el Tribunal Supremo de Justicia de oficio hacer pronunciamiento expresa, para casar el fallo recurrido con base en las infracciones de orden público y constitucionales que ella encontrare, aunque no se les haya denunciado" (subrayado fuera de texto). En cumplimiento de esta norma, el Tribunal Supremo de Justicia ${ }^{23}$ venezolano casa de oficio sentencias que violan la ley"24.

A pesar de este avance, hay una razón desde el punto de vista teórico o dogmático que haría innecesario acudir a la concepción del Estado Social de Derecho para justificar el rechazo del principio dispositivo de la casación.

\subsubsection{Crítica desde el punto de vista teórico o dogmático}

¿Qué pasaba en 1920 en el Derecho Procesal?, ¿cuál fue el contexto histórico en el que el joven Calamandrei escribió su obra? En 1920 la tendencia en el Derecho Procesal la marcaba la obra de Giuseppe Chiovenda, Principios de Derecho Procesal Civil ${ }^{25}$, publicada en 1906, y uno de los pilares de esta obra de Chiovenda fue la teoría del derecho de acción como derecho potestativo, expuesta en 1903 en la famosa conferencia La Acción en el Sistema de los Derechos ${ }^{26}$ en la Universidad de Bolonia. De esta obra tomó Calamandrei el fundamento del principio dispositivo de la casación.

Sobre el principio dispositivo, que reitero para Calamandrei sólo se fundamenta en ser la acción de impugnación de casación un derecho potestativo, con todo el respeto por quien fue Calamandrei, en este particular aspecto hoy es un error dog-

22 DAVID, René. Los Grandes Sistemas Jurídicos Contemporáneos. Edición, traducción y notas de Jorge Sánchez Cordero. México DF: Universidad Nacional Autónoma de México y otros, 2010. p. 4. "El derecho comparado es útil para alcanzar un mejor conocimiento de nuestro derecho nacional y para enriquecerlo".

23 Venezuela. Tribunal Supremo de Justicia, Sala de Casación Social, sentencia del 16 de junio de 2005, num. 630, exp. 04-1826, MP Omar Alfredo Mora Díaz. Disponible en la página Web del Tribunal Supremo de Justiciahttp://www.tsj.gov.ve/decisiones/scs/Junio/0630-160605-041826. htm. Las notas 22 a 23 son de la cita.

24 BONETT ORTIZ, Samir Alberto. Op. cit., pp. 832-833.

25 Traducción española de la $3^{\text {a }}$ ed. italiana. Prólogo y notas del profesor José Casáis y Santoló, Madrid: Editorial Reus SA, 1922.

26 La Acción en el Sistema de los Derechos. 2a ed., Bogotá: Editorial Temis SA, 2011. p. 31: "La acción, un derecho potestativo. La acción es, pues, a mi entender un derecho potestativo..." (mayúscula del texto). 
mático por ser equivocada la tesis que consideraba el derecho de acción, y dentro de este, la acción de impugnación de casación, como un derecho potestativo, como lo criticó y probó la doctrina posterior, como explicó Hernando Devis Echandía ${ }^{27}$. Hoy nadie afirma que el derecho de acción sea un derecho potestativo. La acción de impugnación de casación como derecho potestativo, según Calamandrei, significa que cada petición en el recurso de casación es un derecho del recurrente que se funda en cada violación de la ley por la sentencia, por ejemplo, si la sentencia incurre en tres violaciones del ordenamiento jurídico, el recurrente tiene 3 derechos potestativos y si solo impugna dos violaciones, significa que es ejercicio de su poder no usar el 3 porque es su derecho y la Corte no puede ir más allá del derecho del recurrente. Ese es el fundamento. El error dogmático consiste en que el derecho de acción no es un derecho potestativo y tampoco por derivación la acción de impugnación de casación. Luego, si el derecho de acción no es un derecho potestativo, se derriba el pilar que sostiene el principio dispositivo; luego no se debe aplicar, y debe aplicarse el contrario: el principio iura novit curia ${ }^{28}$ (el juez conoce los derechos).

$\mathrm{Al}$ respecto, “... el maestro Hernando Devis Echandía ${ }^{29}$ explica: «Pero, en cambio, dos observaciones importantes deben hacérsele a su teoría:

$1^{\text {a }}$. Considera él que como el interés perseguido por el actor es privado, también la acción es un derecho privado, como se ve del siguiente párrafo: "La tradición latina vio en la acción especialmente esta dirección contra el adversario e hizo de ella, como nosotros hacemos, un derecho privado, en cuanto privado es también el interés" 30 .

Olvidó en esta parte el ilustre procesalista que la acción no puede ser separada del funcionario que representa al Estado, ante quien se ejercita, y que, precisamente, si es su fin la actuación de la voluntad de la ley y no se puede conseguir esa actuación sino por el juez, como órgano del Estado, es esencialmente una relación entre el actor y el Estado, para el ejercicio de una función pública, de manera que su naturaleza no puede ser privada, sino pública también; lo que se deduce, además, del fin de la jurisdicción y del proceso, que es el interés público del Estado en la realización del derecho (cfr. núms. 20 y 56). Aquí fueron más técnicos los autores alemanes, quienes la consideraron como un derecho subjetivo público.

$2^{\text {a }}$. La noción del derecho potestativo, según la concibe Chiovenda, adolece de demasiada sutileza, y lleva a dos errores consecuentes: a colocar como sujeto pasivo de la acción a la contraparte, que la considera "como aquella que debería sufrir el efecto jurídico considerado como objeto del derecho", y

\footnotetext{
$27 \quad$ Nociones Generales de Derecho Procesal Civil. $2^{\text {a }}$ ed., Bogotá DC: Editorial Temis SA, 2009. pp. 191-192.

28 SENTÍS MELENDO, Santiago. El Juez y el Derecho. Buenos Aires: Editorial Jurídica EuropaAmérica, EJEA, 1957. p. 33.

29 DEVIS ECHANDÍA, Hernando. Op. cit., pp. 191-192.

$30 \quad$ Ibídem., pág. 84. Esta nota es de la cita.
} 
a confundir, si se supone la categoría de los derechos potestativos, el derecho subjetivo con la facultad ${ }^{31}$. Afirmar la existencia de derechos subjetivos sin obligación correlativa para nadie, es desvirtuar su noción jurídica; de la norma que concede el derecho emana la prohibición de vulnerarlo o desconocerlo, y esto constituye la obligación para ese sujeto pasivo determinado o determinable. Lo que es potestativo es ejercitar o no el derecho mismo; y esto sucede con casi todos los derechos, ya que se pueden ejercitar o no, sin que eso desvirtúe la naturaleza real.

En cambio de esforzarse por crear una categoría de derecho en que pueda encajar la acción, más científico y conforme a su real naturaleza es considerarla como un derecho público subjetivo, para un fin público, como vimos al estudiar el proceso y la jurisdicción (cfr. núms. 20 y 56)» (mayúscula del texto), (subrayado fuera de texto)"32.

\subsection{EL PRINCIPIO IURA NOVIT CURIA}

Según Santiago Sentís Melendo 33 , "La traducción de Iura novit curia no puede ser otra que «el juez (la Corte, el Tribunal, el Magistrado o, en general, la autoridad judicial) conoce los derechos»;" (cursiva del texto). Llevado el principio iura novit curia a la casación, tendría como efecto en palabras de Calamandrei ${ }^{34}$ : "Si el recurso del particular fuese solamente el medio para poner en movimiento la Corte de casación en interés público, para excitarla a indagar objetivamente, en utilidad del Estado, si el ordenamiento jurídico ha sido violado por la sentencia denunciada, se podría pensar que la Corte de casación, una vez puesta en movimiento, fuese libre de anular la sentencia también por errores de derecho in iudicando diversos de los puestos de relieve por el recurrente, desde el momento en que la regla Iura novit curia pondría a la Corte de casación en situación de hacer una crítica directa sobre toda la motivación in iure de la sentencia denunciada, y de darse inmediatamente cuenta de todas las violaciones de ley contenidas en ella, aunque hubieran escapado a la crítica del recurrente" (cursiva del texto).

Si Calamandrei no se hubiese equivocado en la fundamentación teórica del principio dispositivo, y no hubiese cometido el gran error teórico (dogmático) e histórico de considerar el derecho de acción como un derecho potestativo y, por consecuencia, también el derecho de impugnación de casación de la sentencia, sin duda, habría concluido que la Corte o Tribunal de Casación si podría actuar de oficio o que en la casación es aplicable el principio iura novit curia. Y de haberlo dicho

\footnotetext{
31 CARNELUTTI, Sistema, t. II, núm. 356. Esta nota es de la cita. Las notas 29 a 31 son de la cita.

32 BONETT ORTIZ, Samir Alberto. Op. cit., pp. 831-832.

33 SENTÍS MELENDO, Santiago. Op. cit., p. 17.

34 CALAMANDREI, Piero. Op. cit., p. 172.
} 
así, todos lo habrían seguido y no existiría el problema de siempre de pasividad de la Corte o Tribunal de Casación.

\subsection{Propuesta}

Si el desconocimiento del error de la fundamentación teórica del principio dispositivo de la casación que hizo Piero Calamandrei es un grave error histórico en el derecho procesal, es igual o más grave mantenerlo con el pretexto de la grandeza y autoridad de Calamandrei y su obra de juventud y de la tradición procesal. Luego, hay que rechazar el principio dispositivo para que la Corte o Tribunal de Casación pueda actuar de oficio aplicando el principio iura novit curia.

\section{Conclusiones}

1. La fundamentación teórica del principio dispositivo de la casación que hizo Piero Calamandrei fue incorrecta porque el derecho de acción no es un derecho potestativo y, por consecuencia, el derecho de impugnación de casación de la sentencia tampoco lo es. Luego, debe ser rechazada por la normativa, jurisprudencia y doctrina.

2. En lugar de aplicar el principio dispositivo en la casación, es más coherente con sus fines el uso del principio iura novit curia. Esta idea es aplicable a la casación civil, laboral y penal.

\section{REFERENCIAS}

BONETT ORTIZ, Samir Alberto. "La Casación Laboral Justa". En: XXXIII Congreso Colombiano de Derecho Procesal. Cartagena de Indias, 2012. Memorias.

CALAMANDREI, Piero. Instituciones de Derecho Procesal Civil. Volumen III. Traducción de Santiago Sentís Melendo, Buenos Aires: Librería El Foro SA, 1996.

La Casación Civil. Tomos I y III. Traducción de Santiago Sentís Melendo, Buenos Aires: Librería El Foro, 2007.

CHIOVENDA, Giuseppe. La Acción en el Sistema de los Derechos. $2^{a}$ ed., Bogotá: Editorial Temis SA, 2011.

Principios de Derecho Procesal Civil. Tomo I. Traducción española de la $3^{\mathrm{a}}$ ed. italiana. Prólogo y notas del profesor José Casáis y Santoló, Madrid: Editorial Reus SA, 1922.

DAVID, René. Los Grandes Sistemas Jurídicos Contemporáneos. Edición, traducción y notas de Jorge Sánchez Cordero. México: Universidad Nacional Autónoma de México y otros, 2010. 
DEVIS ECHANDÍA, Hernando. Nociones Generales de Derecho Procesal Civil. 2a ed., Bogotá DC: Editorial Temis SA, 2009.

MORALES MOLINA, Hernando. Técnica de Casación Civil. 2a ed., (edición privada).

MURCIA BALLÉN, Humberto. Recurso de Casación Civil. 2a ed., Bogotá: Editorial Temis Librería, 1978.

NIEVA FENOLL, Jordi. "La Relevancia Social de la Casación: la Importancia del Ius Litigatoris". En: XXVII Congreso Colombiano de Derecho Procesal. Cartagena de Indias, 2006. Memorias.

PALACIO, Lino Enrique. Manual de Derecho Procesal Civil. 19ª ed., reimpresión, Buenos Aires: Abeledo Perrot S.A., 2009.

SENTÍS MELENDO, Santiago. El Juez y el Derecho. Buenos Aires: Editorial Jurídica Europa-América, EJEA, 1957.

\section{Jurisprudencia}

Colombia. Corte Constitucional, sentencia T-1306 del 6 de diciembre de 2001, M.P. Marco Gerardo Monroy Cabra.

Colombia. Corte Suprema de Justicia, Sala de Casación Civil y Agraria, sentencia del 23 de marzo de 2000, exp. 5259, M.P. Carlos Ignacio Jaramillo Jaramillo.

Venezuela. Tribunal Supremo de Justicia, Sala de Casación Social, sentencia del 16 de junio de 2005, num. 630, exp. 04-1826, M.P. Omar Alfredo Mora Díaz. Disponible en la página Web del Tribunal Supremo de Justicia: http://www.tsj.gov. ve/decisiones/scs/Junio/0630-160605-041826.htm 
Procesal CONSTitucional 